\title{
UM OLHAR SOB A ÓTICA DA RAZÃO E DA FÉ
}

Márcio Fabri dos Anjos*

Em meio a um assunto tão debatido, o que nos chama a atenção aqui é a reflexão ética sobre a pena de morte. A ética é uma ciência que assume critérios e analisa os valores envolvidos na ação humana, transformando-os em razões para agirmos. Por isso mesmo, ela nos leva a concluir pelo sim ou pelo não de nossas açóes. Então, o que nos interessa neste artigo é sondar critérios e razões em torno da pena de morte. Com base na inspiração da fé cristã. Como não é possível ser completo, sem tornar esse artigo pesado, vamos examinar alguns grupos de razões, sua forma e sua validade. 


\section{O JULGAMENTO DO CORAÇÃO}

A discussão sobre pena de morte começa por um lado muito emocional. Isto é compreensível, pois estamos tratando de algo que nos toca por dentro, a nossa propria vida e o mundo de nossas relações. Este lado da discussão aparece muito claro quando sentimos nossa vida ameaçada pela violência que nos rodeia. Queremos naturalmente punir e anular esta ameaça. A emoção pede a pena de morte.

Mas existe também a emoção numa direção contrária. Se olhamos a vida pelo lado de quem vai ser executado, a pena de morte se torna dramática e repugnante. Vemos a vida como uma história dinâmica, que por mais errada que tenha sido, tem chance de tomar outro rumo. Aqui a emoção é contra a pena de morte.

Estes dois lados estão resumidos numa discussão real sobre o assunto: Um conferencista se mostrava contra a pena de morte, quando um dos participantes reagiu com indignação:

- "Se um estuprador violentasse e matasse sua irmã, você não seria a favor da pena de morte?"

O conferencista respondeu com tranqüilidade:

- "E se o estuprador fosse seu irmão, você executaria a pena de morte?"

Uma primeira conclusão parece clara: a ética da pena de morte passa pelo coração. No fundo, a questão é se julgamos com um coração indignado ou com um coração compassivo.

\section{RAZÃO RANCOROSA}

Com base num coração indignado, a reflexão ética sobre a pena de morte tem um argumento muito antigo a seu favor. Está na idéia de fazero réu pagar pelo mal que fez. Trata-se de uma punição vindicativa. Este conceito está muito presente na expressão popular de "fazer justiça", quando simplesmente queremos que os maus sejam punidos.
Em culturas muito antigas como a semita esta razão para a pena de morte se confunde com as vinganças familiares em que os parentes tinham que vingar a morte ou o mal feito a alguém de sua família. As sociedades foram moderando essas vinganças através da conhecida "lei do talião" (Olho por olho, dente por dente). Esta lei, na verdade, tentava impedir que a vingança fosse exagerada e maior do que o mal recebido. Vieram em seguida as leis sociais estabelecendo os casos em que a pena de morte podia ser aplicada.

A própria Bíblia mostra os sinais desse momento cultural. (1) A aplicação da pena de morte é ali reconhecida para o homicida, o seqüestrador, o que fere seus pais, o que fere uma mulher grávida, os adúlteros, homossexuais, incestuosos, estupradores, idólatras, blasfemos, violadores do sábado, feiticeiros e para a filha do sacerdote que se prostituir. (2) Ao mesmo tempo, procura-se defender da vinganca de morte a quem mata por acidente. (3)

Além da concepção de vingança familiar, é preciso acrescentar também a mentalidade mágica e sacral daquele momento cultural. Por ela se entende que um crime desencadeia um processo de forças negativas no meio ambiente. Dentro desse contexto, matar o criminoso ou o violador, é uma questão de necessidade para se "limpar a barra" diante da divindade. Especialmente no caso do homicida, pois entende-se que a vida é sopro divino que sustenta a carne em sua fragilidade. Ora, quem extingue este sopro vital, insulta diretamente a divindade e por isso deve morrer também.

Esta legitimação da pena de morte através da "razão rancorosa", tem portanto um momento cultural muito claro que vai se prolongando através da história da humanidade. Teve momentos fortes também na Idade Média. Hoje ainda ela continua presente, talvez não mais pelo seu lado sacral, mas principalmente pelo desejo incontido de punir e vingar.

Sob o ponto de vista ético, na medi- da em que as culturas vão evoluindo, descobrem que a idéia de punição como vingança não constrói a humanidade. Neste sentido, a Bíblia espelha a revelação progressiva do desejo de Deus para a humanidade, diante do crime. Deus "não quer a morte do pecador, mas sim que ele se converta e viva"; na verdade, Deus "não tem prazer na morte de quem quer que seja". ${ }^{(4)}$ E Jesus irá levar à plenitude essa mensagem colocando a promoção da vida de todos como o centro de sua vinda ao mundo: "Eu vim para que todos tenham vida e a tenham em abundância".(5) Jesus propõe o amor aos próprios inimigos e chama de "dureza do coração", o querer ficar estagnado na lei do talião e nas prescrições legais. ${ }^{(6)}$

Podemos concluir que, diante da fé cristã já não há espaço para justificar a pena de morte como punição. As razões da fé levam a se fazer da história da humanidade uma história de vida e não de morte. Por isso, sua preocupação fundamental é a de transformar a vida do criminoso, para que ele deixe o crime. Diante da simples razão humana, a pena de morte como punição também é um contrasenso. Como diz o povo, "a vida continua". Então, depois do crime, por que matar o criminoso? A pena de morte resolve o passado, quando na verdade a vida é para frente! Isto nos leva a deslocar a pergunta. Não tem sentido buscar um porquê da pena de morte. É preciso perguntar para que ela pode servir.

\section{PENA DE MORTE: UMA RAZÃO SOCIAL?}

D escartadas as razões rancorosas para a pena de morte, a reflexão ética clássica procura estabelecer o "para que" ela pode servir. Neste caso, a pena de morte seria para proteger 0 bem comum. ${ }^{(7)}$ Significaria defender a segurança de todos e para garantir os direitos dos cidadãos. A pena de morte funcionaria então não como punição, mas como defesa do bem comum: por 
um lado ela seria como que "medicinal", extirpando membros maus de seu meio, como se faz em operações cirúrgicas; por outro lado, seria "exemplar", desencorajando outras pessoas a praticarem os crimes.

Esse modo de ver uma função social para a pena de morte tem vigorado como argumento para sustentá-la em muitos países. Mesmo na Igreja, por muito tempo se achou que esta razão seria suficiente para se admitir a moralidade da pena de morte ao menos em teoria. ${ }^{(8)}$ Entretanto, essa forma de ver esbarra hoje com graves questões:

a) Quando falamos de "bem comum", ao passarmos da teoria para os fatos, o bem comum facilmente toma forma de "ordem social estabelecida". Neste caso, criam-se privilégios para alguns e a desgraça para outros, que não podem protestar porque estariam contra o "bem comum". Cinicamente a sociedade chama estes últimos de "menos favorecidos". A primeira pergunta que fica então é: ao aplicar a pena de morte não estamos eliminando cinicamente os próprios marginalizados pela sociedade?

b) Outro desdobramento desta primeira consideração é o seguinte: o contexto de violência em que se situam os crimes pode ser exatamente produção da "ordem estabelecida". Os criminosos não seriam necessariamente pessoas marginalizadas e pobres, mas "gente fina". Mas é a sociedade que ensina a violência de muitas formas, desde a luta pelos salários até mesmo no prazer de se assistir a um programa de televisão. Neste caso, a pena de morte é uma solução? Pode ser considerada "medicina"? Ou não é fuga ao desafio de enfrentar questões mais sérias como o clima de agressão à vida que a própria sociedade produz? Assim a pena de morte, além de não ser solução, seria simplesmente uma violência a mais (legalizada como tantas outras).

c) Muitas estatísticas comprovam que a "exemplariedade" não funciona nos países que adotam a pena de morte. Isto $\ell$, os crimes não diminuem por haver pena capital. Ao contrário, de certa forma até aumentam, pela preocupação de o criminoso eliminar possíveis testemunhas contra ele.

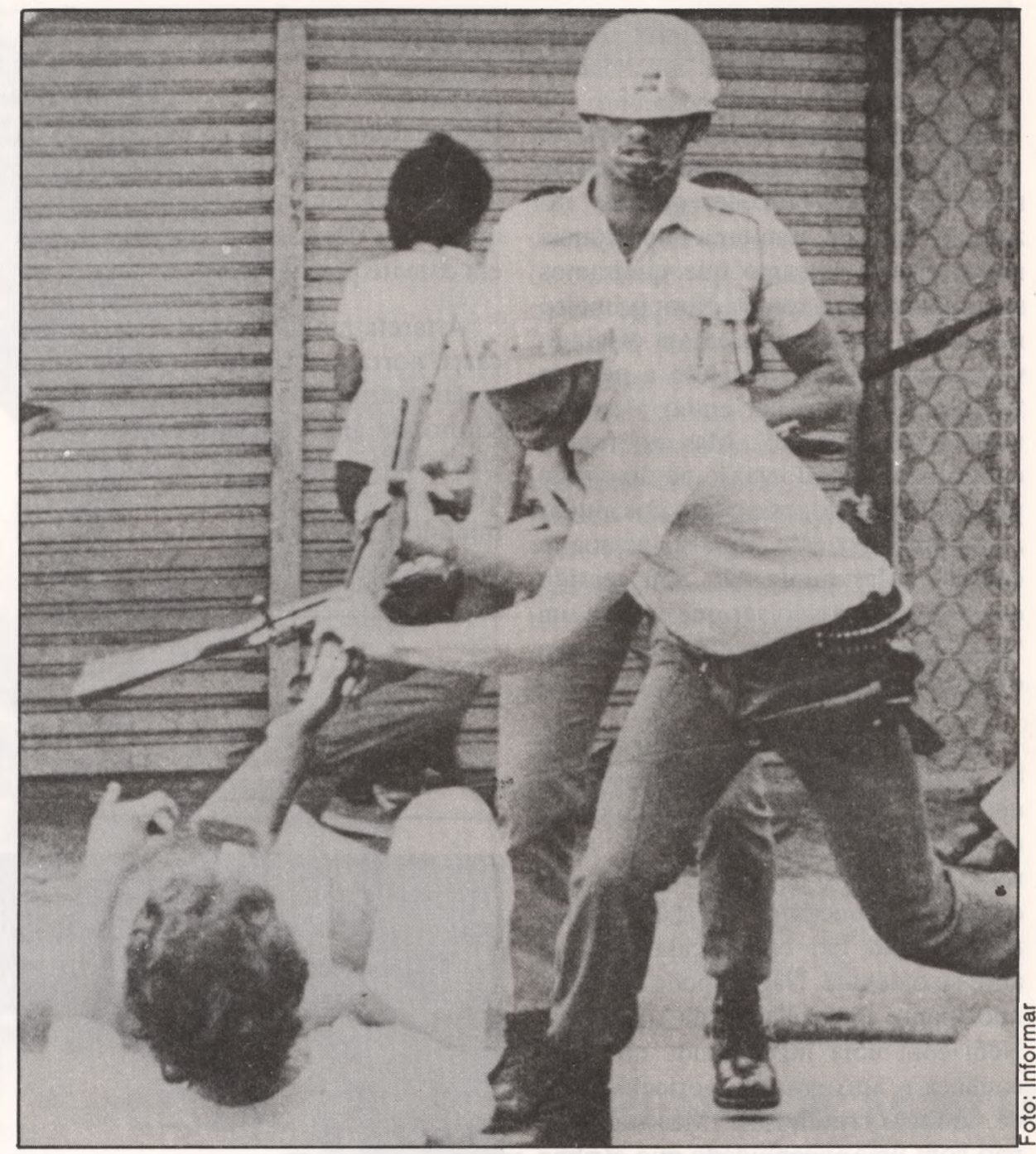

d) Se de fato a pena de morte visa proteger a sociedade, será que não temos hoje meios mais modernos para isso? Uma resposta mais uma vez cínica seria usar a tecnologia moderna simplesmente para matar de modo mais sofisticado, com mais rapidez e sem dor. Obviamente não se trata disso. Trata-se de procurar a recuperação dos criminosos e a defesa da vida na sociedade, sem precisar apelar para a morte. É incrível que uma civilização tão orgulhosa como a nossa, de ser avançada e progressista, abdique tão facilmente de colocar a ciência e tecnologia a serviço da vida.

e) Resta por fim o erro jurídico, verificado muitas vezes, pelo qual se aplica a pena de morte a pessoas inocentes. A possibilidade do erro jurídico mostra mais uma vez como a violência da pena de morte pouco ajuda para construir a vida social.
Diante destas considerações, podemos compreender e admitir que algumas sociedades concretamente não tenham conseguido defender os valores fundamentais da vida em suas relações sociais, sem recorrer à pena de morte. Por isso, consideraram esta pena um mal menor eticamente aceitável. O erro nosso consistiria em copiar simplesmente as avaliações e conclusões do passado. Os tempos são outros, as análises e a compreensão dos processos da vida são diferentes, e os recursos de que dispomos têm outro alcance.

Em síntese, podemos dizer que a pena de morte atualmente no Brasil é anti-ética ao menos por dois motivos inter-relacionados: ao mesmo tempo em que representa fuga de enfrentar as raízes da violência em nossa sociedade, serve para alimentar a espiral de violência estabelecida. 


\section{COM FÉ E CORAÇÃO}

No conjunto dos argumentos e de todo o debate sobre a pena de morte, devemos perceber que as "razões do coração" têm uma importância muito grande. Mesmo que queiramos ser objetivos e racionais. Num primeiro momento, elas se apresentam exigindo vingança do crime. Quando a palavra "vingança" incomoda, então a substituímos por "justiça". Mas no fundo, continuamos dando vazão ao desejo de punir. Os psicologos podem nos ajudar a compreender esse impulso pessoal e coletivo. Mas punir não tem sentido em si mesmo, a não ser que tivesse um "para que" satisfatório que superasse a dimensão de punição.

Aí entra a razão apontando a pena de morte como recurso extremo para defender a sociedade, extirpando o mal de seu meio e convencendo os "futuros" criminosos de que o crimé não compensa. Funciona? A razão moderna não está tão convencida disso, e abre-se o debate. Não se pode ser ingênuo diante da violência na sociedade. Nem com uma ingenuidade que desconheça o alto grau de periculosidade de muitos criminosos. Mas também não com uma ingenuidade que atribua a violência a simples iniciativa dos criminosos. Há criminosos, e como vamos superar esse fato em nossa sociedade, aí está o desafio.

Nesse ponto, as razões continuam dialogando com o coração. A fé cristã fala que Deus promete "tirar o nosso coração de pedra e substitui-lo por um coração de carne". ${ }^{(9)}$ Aqui retomamos um ponto chave da reflexão ética sobre a pena de morte. "Trocando de coração", ișto é, deixando de lado o coração rancoroso e vingativo, começamos a ser capazes de perceber as pessoas por trás dos crimes. Descobrimos não só as vítimas, mas também os criminosos com uma história de vida que desafia a se fazer história de dignidade humana. É nisto que a fé cristã desequilibra os argumentos: ela coloca qualquer pessoa como alguém chamado a participar da liberdade dos filhos de Deus. Uma sín- tese de tudo isso está no julgamento da adúltera, no Evangelho (Jo.8,1-11): Trata-se de um caso de pena de morte que Jesus desmascara e o transforma em convite para viver.

A tarefa moral que daí decorre descarta, portanto, a pena de morte como razão instrumental de defesa da vida $\mathrm{e}$ se propõe antes enfrentar as raízes da violência na sociedade. $\mathrm{E}$ diante dos que estão no crime, não se trata de eliminá-los, mas de buscar como conquistá-los para o grande banquete da vida.

* Márcio F. dos Anjos é padre redentorista, doutor em Teologia, presidente da Sociedade de Teologia e Ciências da Religião (SOTER) do Brasil e prof. de Teologia Moral em São Paulo.

\section{NOTAS}

1. A lei do talião está muito clara em Ex.21,23-27; Lv.24, 18-22; Dt.19,21. De resto, veja Clemens Thomas, $A$ pena de morte e a tortura na tradiçāo judaica, in Concilium 140, 1978, 1273-1284.

2. Seria longo trazer aqui todas as citaçōes bíblicas a esse respeito. Veja principalmente Ex.20-21 e Lv.20.

3. Dt. 19,1 ss.

4. Veja correspondentemente Ez. 33,11 e Ez. 18,21-32.

5. Jo.10,10.

6. Veja Mt. 5,20-48; Mt. 19,8.

7. Esse argumento clássico é desenvolvido por Sto. Tomás de Aquino na S.T., II-IIae, q. $64, \mathrm{a} 2$.

8. Veja Márcio F. dos Anjos, Pena de morte na argumentação teológica, in Boletim da CNBB 9.8.91, Encarte 66.

9. Ez. 11,19

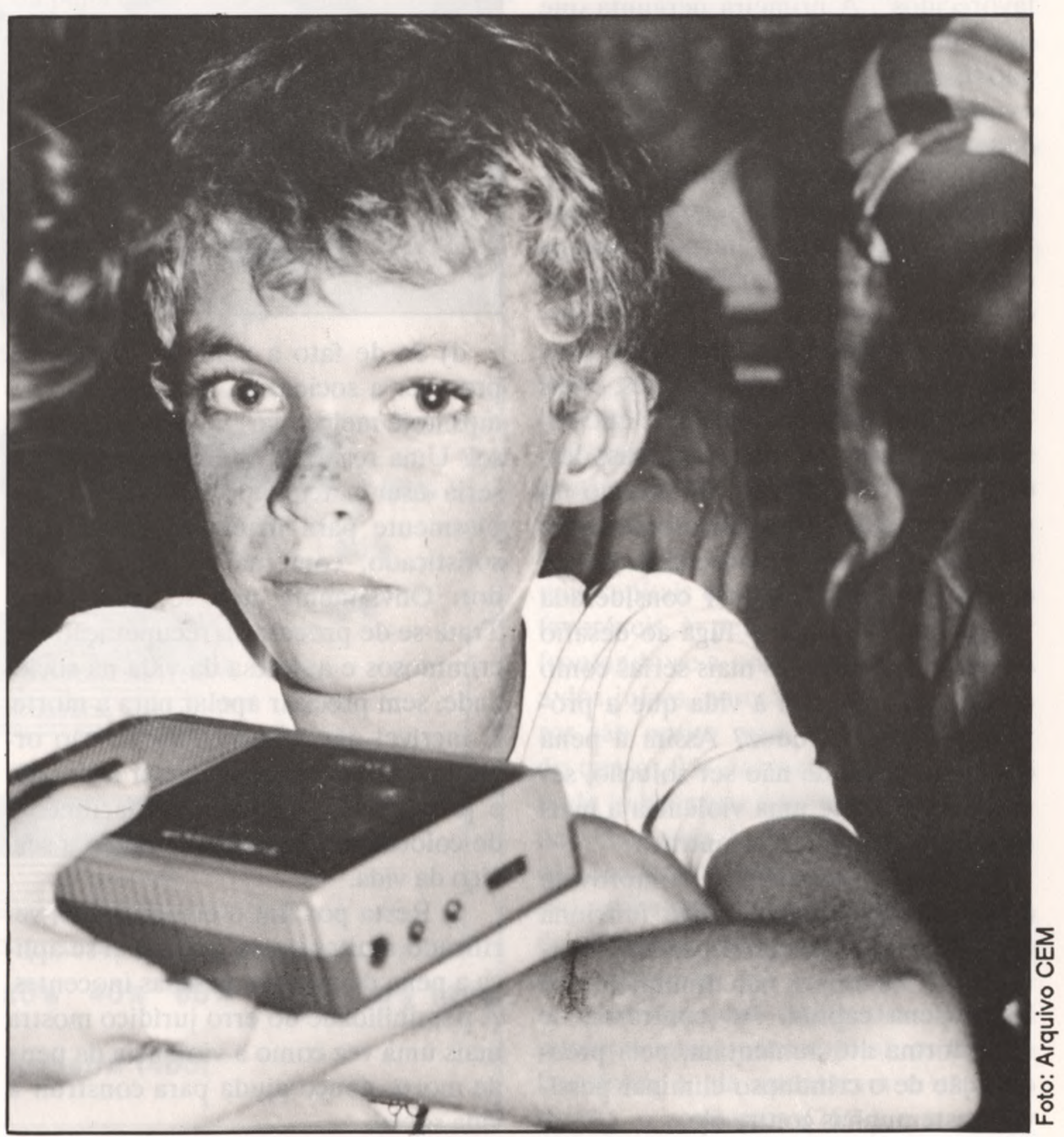

